\title{
Advanced Fault-Tolerant Control of Induction-Motor Drives for EV/HEV Traction Applications: From Conventional to Modern and Intelligent Control Techniques
}

\author{
Mohamed El Hachemi Benbouzid, Senior Member, IEEE, Demba Diallo, Senior Member, IEEE,
} and Mounir Zeraoulia, Student Member, IEEE

\begin{abstract}
This paper describes active fault-tolerant control systems for a high-performance induction-motor drive that propels an electrical vehicle (EV) or a hybrid one (HEV). The proposed systems adaptively reorganize themselves in the event of sensor loss or sensor recovery to sustain the best control performance, given the complement of remaining sensors. Moreover, the developed systems take into account the controller-transition smoothness, in terms of speed and torque transients. The two proposed fault-tolerant control strategies have been simulated on a $4-\mathrm{kW}$ induction-motor drive, and speed and torque responses have been carried to evaluate the consistency and the performance of the proposed approaches. Simulation results, in terms of speed and torque responses, show the global effectiveness of the proposed approaches, particularly the one based on modern and intelligent control techniques in terms of speed and torque smoothness.
\end{abstract}

Index Terms-Automotive application, fault-tolerant control, induction-motor drive.

\section{INTRODUCTION}

$\mathbf{S}$ EVERAL failures can afflict electrical-motor drives, and many different remedial techniques have been proposed. Therefore, far, redundant, or conservative design has been used in industrial applications, where continuity of operations is a key feature. This is especially important in highimpact automotive applications, such as electrical vehicles (EVs) and hybrid EVs (HEVs), where the drive system must feature, among others, high reliability and robustness for various vehicle-operating conditions. Because even limp-back operation is preferred over no operation, the remedial techniques may lead to short-torque transients and even to permanently reduced drive performance after fault, on the condition that the drive still goes running.

This paper describes an active fault-tolerant control system for a high-performance induction-motor drive that propels an

Manuscript received July 3, 2005; revised March 20, 2006 and March 31, 2006. The review of this paper was coordinated by Prof. A. Emadi.

M. E. H. Benbouzid and M. Zeraoulia are with the Laboratoire d'Ingénierie Mécanique et Electrique (LIME), Electrical Engineering Department, IUT of Brest, University of Western Brittany, 29231 Brest Cedex 3, France (e-mail: m.benbouzid@ieee.org).

D. Diallo is with the Laboratoire de Génie Electrique de Paris (LGEP), CNRS UMR 8507, University Paris Sud, Supélec, University Paris VI, 91192 Gif-Sur-Yvette, France (e-mail: ddiallo@ieee.org).

Color versions of one or more of the figures in this paper are available online at http://ieeexplore.ieee.org.

Digital Object Identifier 10.1109/TVT.2006.889579
EV or an HEV. The proposed system adaptively reorganizes itself in the event of sensor loss or sensor recovery to sustain the best control performance, given the complement of remaining sensors. Moreover, the developed system takes into account the controller-transition smoothness, in terms of speed and torque transients. The first approach proposed is concerned with conventional control techniques [1]. In this case, four control strategies are used to achieve fault-tolerance: indirect vector control (IVC), sensorless vector control (SVC), sensorless scalar control (SSC), and Volts/Hertz open-loop control. The second approach is concerned with modern and intelligent control techniques [2]. Two control techniques have been chosen to illustrate the fault-tolerance consistency: sliding mode for encoder-based control and fuzzy logics (fuzzy voltage-boost control) for sensorless control. In this second case, the systemcontrol reorganization is managed by a fuzzy-decision system that assures smooth transition from a controller to another one.

Simulation tests, in terms of speed and torque responses, have been carried out on the same 4-kW induction-motor drive to compare the consistency of the two fault-tolerant control approaches.

\section{EV AND HEV DRIVES CONTROL}

Automotive-application drives such as in EV and HEV have some major requirements that are summarized as follows [3], [4]:

1) high instant power and high power density;

2) high torque at low speeds for starting and climbing, as well as high power at high speed for cruising;

3 ) very wide speed range including constant-torque and constant-power regions;

4) fast torque response;

5) high efficiency over wide speed and torque ranges;

6) high efficiency for regenerative braking;

7) high reliability and robustness for various vehicleoperating conditions; and

8) reasonable cost.

The main requirement that is related to the electricpropulsion control is the ability to operate at constant power over a wide speed range, good overload performance, and high efficiency, especially at light-load operation at higher speeds (Fig. 1). These characteristics allow the best utilization of the 


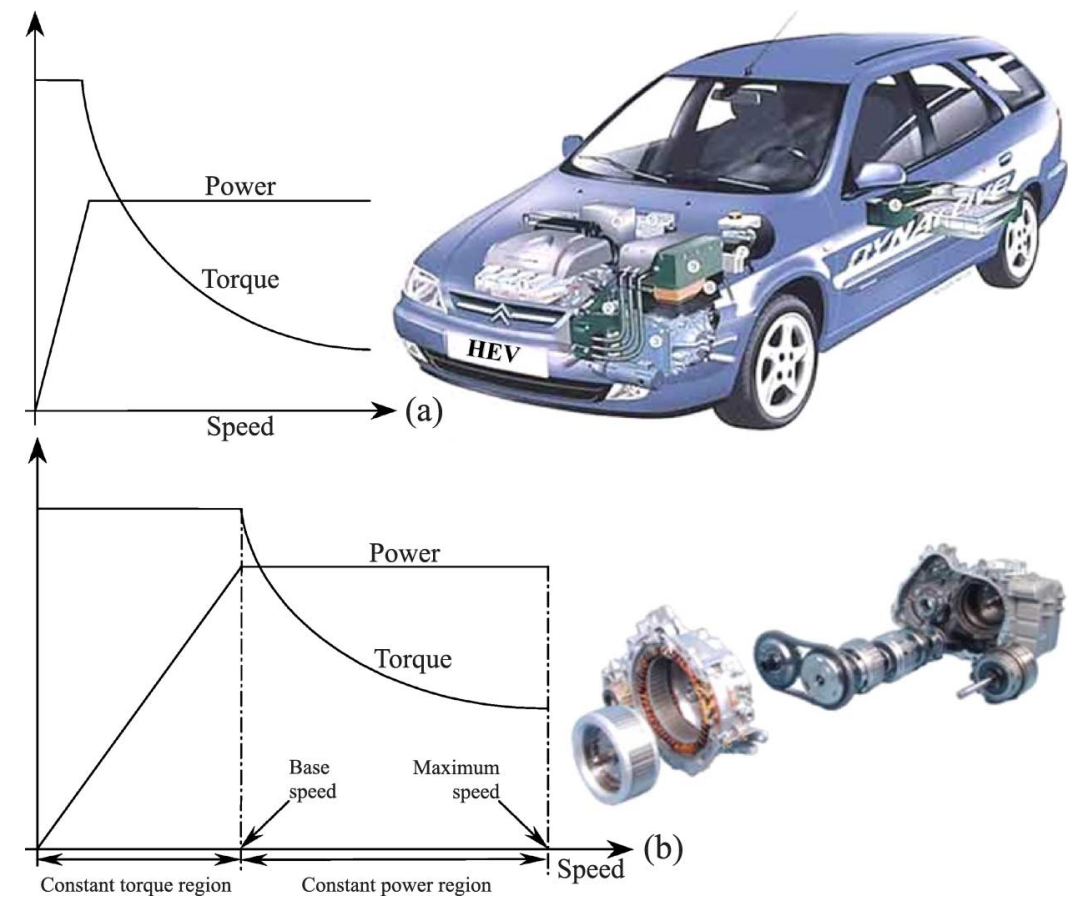

Fig. 1. HEV typical characteristics: (a) Tractive effort versus speed. (b) Electric traction.

limited battery capacity (extension of the running-distance-perbattery charge) and the minimization of the size and the weight of the motor and the drive.

Cage induction motors are widely accepted as the most potential candidate for the electric propulsion of EVs and HEVs due to their reliability, ruggedness, low maintenance, low cost, and ability to operate in hostile environments. They are particularly well suited for the rigors of industrial and tractiondrive environments [5]. Today, induction-motor drive is the most mature technology of all commutatorless motor drives. Moreover, the cage induction motor seems to be the candidate that best fulfils the major requirements of automotive electric traction [6].

Induction-motor drives control techniques are well treated in the literature [7]. The most popular is the so-called scalarcontrol method. This technique allows great performances only in steady state, because precise control of the instantaneous torque is not possible. The vector-control technique is now used for high-impact automotive applications (EV and HEV). In this case, the torque control is extended to transient states and allows better dynamic performances [8]-[14].

Depending upon the application and availability of sensors and the desired performance of the system, there are many hybrid schemes that could be combined for fault-tolerant purposes [9], [14]. However, conventional linear control such as proportional integral derivative (PID) can no longer satisfy the stringent requirements placed on high-performance EVs or HEVs. In recent years, many modern control strategies such as model-referencing adaptive control (MRAC), self-tuning control (STC), sliding-mode control (SMC), fuzzy control (FC), and neural-network control (NNC) have been proposed [15]. Both MRAC and STC have been successfully applied to EV propulsion [16]. Using sliding mode, SMC has also been applied to motor drives [17]-[19]. By employing emerging tech- nologies of fuzzy and neural networks to achieve the concept of intelligent controllers, NNC [20]-[22] and FC [23]-[28] have promising applications to EV and $\mathrm{HEV}$ propulsion. However, either fuzzy-logic control or artificial neural network has its own drawbacks, which cannot be avoided and neglected. A simple fuzzy controller implemented in the motor drive-speed control has a narrow speed operation and needs much manual adjusting by trial and error, if high performance is wanted. On the other hand, it is extremely tough to create a series of training data for neural networks that can handle all the operating modes. Neuro-FC, which have advantages of both FC and NNC are, therefore, adopted in some cases for inductionmotor control [29], [30].

The need of a good management of the onboard energy calls for efficiency-optimization control techniques. Indeed, it should be noted that classical induction-motor control techniques, such as vector control, are not sufficient to achieve this goal. Therefore, control techniques that maximize the induction-motor efficiency are highly desirable for the fault-tolerant controller [8], [22], [29], [31]-[35].

\section{FAULT-TOLERANT CONTROL?}

\section{A. Definition}

The concept of a fault-tolerant drive system is that it will continue to operate in a satisfactory manner after sustaining a fault. The term satisfactory implies a minimum level of performance after the fault and will, therefore, be heavily influenced by system requirements [36], [37].

\section{B. Brief Review}

Many efforts have recently been devoted to study faulttolerant control systems, for instance, control systems able to 
detect incipient faults in sensors and/or actuators on the one hand and, on the other, to promptly adapt the control law in such a way as to preserve prespecified performances in terms of quality of the production, safety, etc. The need for these faulttolerant systems has inspired much research for the particular case of standard three-phase induction motors [38]-[43]. The majority of these contributions have been focused on faults in the drive-motor system. Where previous industrial attempts were focused on the actual drive, the current trend is to include sensors and application-fault modes [44], [45]. Indeed, the overall performance of induction-motor drives with a feedback structure depends not only on the health of the motor itself but also on the performance of the driving circuits and sensors: the encoder, voltage sensors, and current sensors.

For induction-motor-drive fault tolerance, two control approaches have been investigated. In the first one, resilient control (also known as accommodation) of the drive system is adopted while retaining the same basic control strategy. In this case, the controller adapts its properties to regulate the motor output as desired by the drive system even under faults conditions [38], [46]. In the second approach, as described in [47], the control system tolerates the faults by changing the control algorithm. In this way, the drive system gives degraded performance, depending on the faults.

\section{Automotive Case}

Electric propulsion is to interface electric supply with vehicle wheels, transferring energy in either direction as required, with high efficiency, under control of the driver at all times. From the functional point of view, an electric-propulsion system can be divided into two parts-electrical and mechanical. The electrical part includes the motor, power converter, and electronic controller. On the other hand, the mechanical part consists of the transmission device and wheels, as illustrated by Fig. 2. Electric propulsion, which is a major-power electronics area, plays a very important role not only in EVs but also in HEVs. In this paper, it is considered as the vehicle heart that should be fault-tolerant.

For EV- and HEV-traction control, fault detection and fault tolerance are important issues not only for the reliability of the drive system but also for the proper operation of the vehicle following a fault. Unfortunately, the automotive literature is not so rich, particularly for vehicles propelled by an induction motor [47]-[51]. In the following, the compared approaches are based on a flexible controller architecture (the second fault-tolerant control approach) that maintains maximum performance in the event of sensor loss or sensor recovery in the EV or the HEV electric drive. To achieve this goal, a reorganizing controller will adopt the best control methodology, depending on the available feedback and operational hardware. Therefore, the reorganizing or fault-tolerant controller, whose location is given in Fig. 3, in case of a parallel HEV, comprises two parts: the fault-detection and isolation (FDI) block that collects status and information from sensors to evaluate the system actual state (e.g., the inverter, the throttle actuator, etc.) and a supervision block that makes the decision on the best fallback strategy by engaging the most appropriate control strategy based on a hierarchical basis.

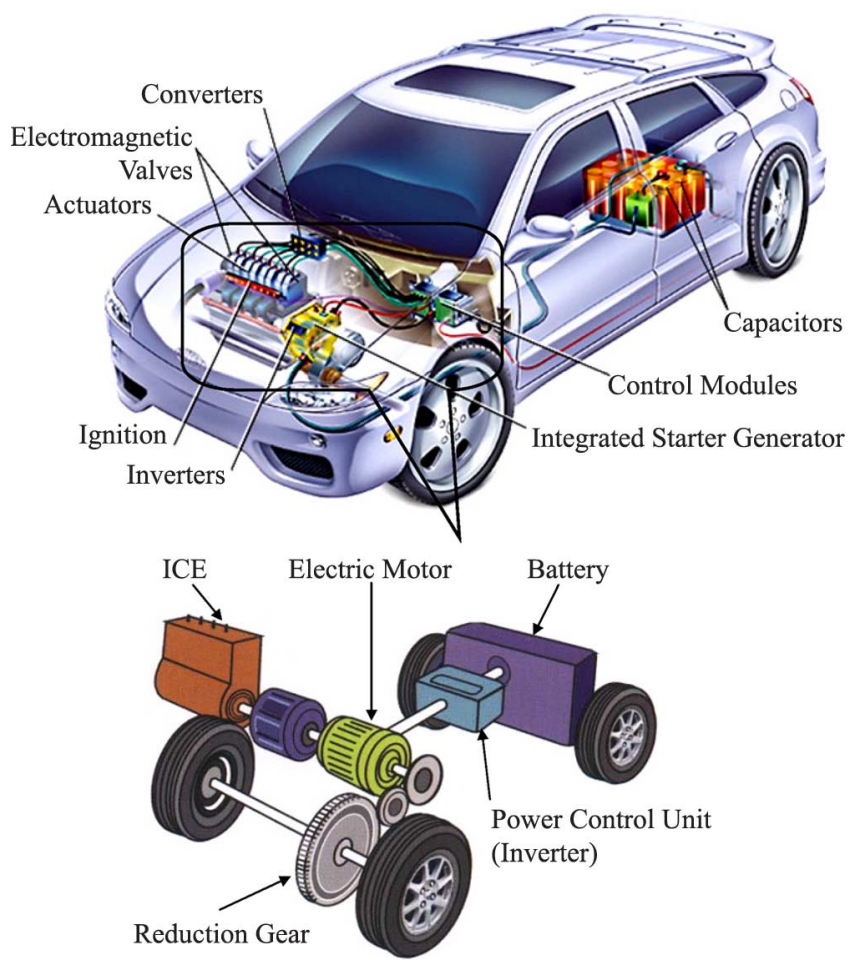

Fig. 2. Some details of the electric propulsion in case of a parallel HEV.

\section{Fault-Tolerant Control With Conventional Techniques}

In order to obtain high-performance motor drives, modern control strategies like field-oriented control should be employed [9], [15]. These techniques are inherently dependent on the measurement devices, or sensors, that should operate properly. However, when these sensors fail, the control system needs to compensate for the failure to function properly. This necessitates the backup systems to support the proper operation of the drive in case of sensor failure. Therefore, the faulttolerant control system first concerns IVC technique, since better performance is obtained with an encoder to get the speed information. In the event of unavailability of the speed sensor (e.g., failures in measurements or in the device), an SVC technique is applied [52]. However, in the high-speed range, angular delay between the control and the motor frames becomes so important that instability may occur. Therefore, even if dynamic performance is reduced, we have to use the closed-loop SSC that guarantees the stability. Finally, if unfortunately the current sensors are ineffective, an open-loop $V / f$ law will be used to avoid complete loss of the process or the engine stopping in an EV or an HEV.

Fig. 4 shows the proposed flexible architecture for faulttolerant control purposes that maintains maximum performance and the overall system failure rate at an acceptable level.

\section{A. Controller-Transition Strategy}

The control-transition smoothness depends greatly upon the rotor-flux-angular position in the stator reference frame. In fact, the flux-angle generator runs in parallel and integrates the motor 


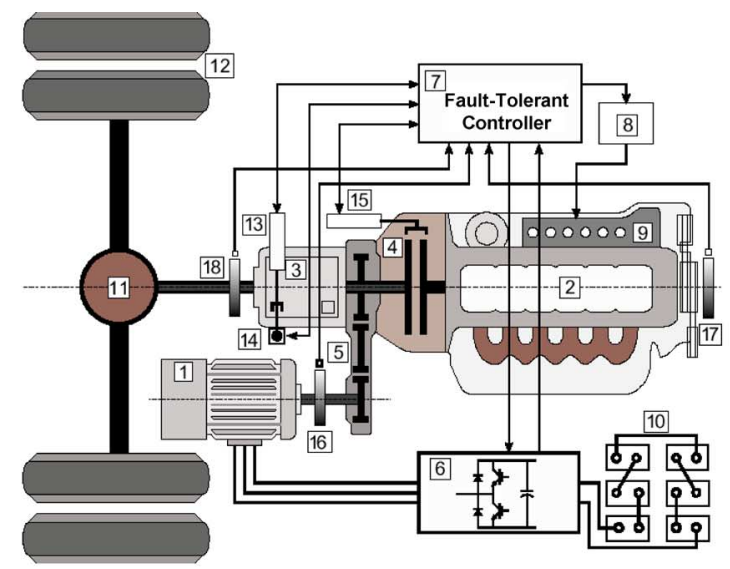

1. Induction motor, 2. ICE, 3. Transmission, 4. Clutch, 5. Inlet gearing, 6. Inverter,

7. Fault-tolerant controller, 8. Throttle actuator, 9. Electronic fuel injector, 10. Battery,

11. Differential gear, 12. Wheels, 13. Horizontal pneumatic actuator, 14. Vertical pneumatic actuator,

15. Clutch pneumatic actuator, 16,17 , and 18 . Saw-tooth wheel.

Fig. 3. Schematic block diagram of a hybrid drive train.

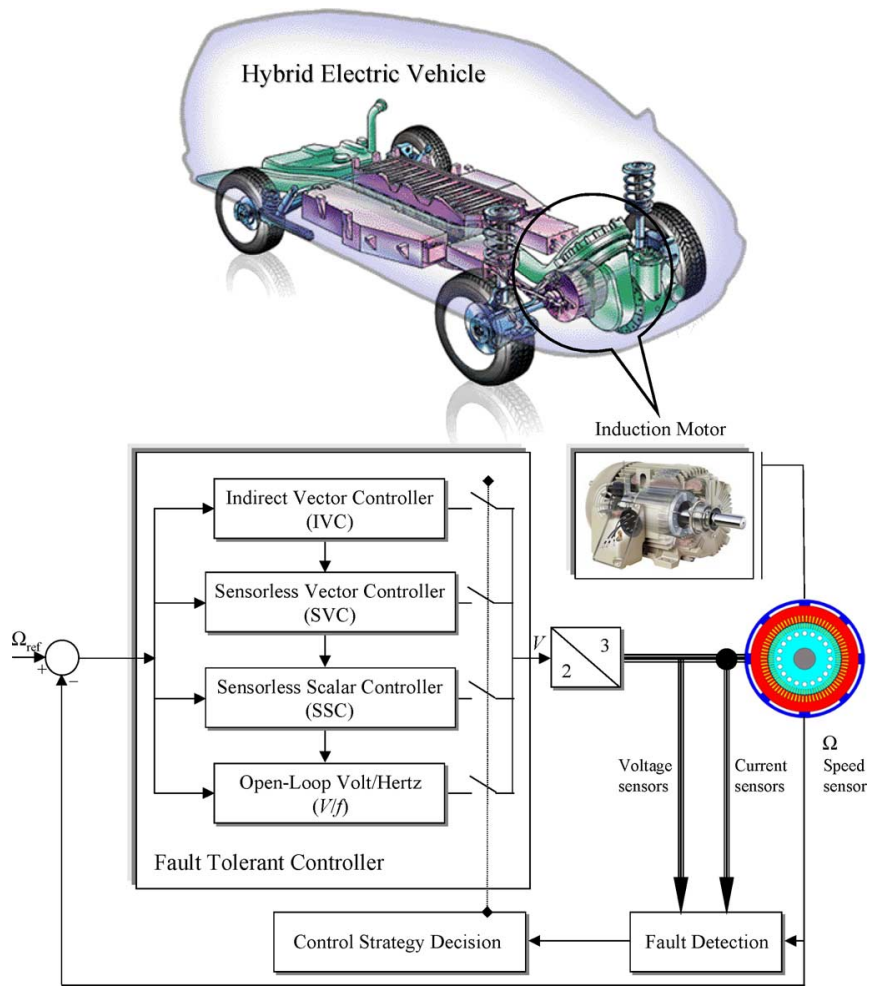

Fig. 4. Overall system structure.

voltage to determine the motor flux. This calculated flux is not used by the IVC controller, but it is available in the event that a switchover to the SVC controller is required. Depending on the control-technique type

$$
\theta_{s}=\int \omega_{s} d t
$$

the calculated angles for SVC or SSC techniques reveal a slight difference. However, if a transition strategy is not used, an important braking torque with probably mechanical damages will occur. Indeed, this braking torque is a direct consequence of the phase-shift between the control voltages $V$ that are the sinusoidal modulating voltages for the pulse-width-modulation (PWM) signal generation. To obtain a smooth transition, this should be done when the phase-shift $\Delta \theta$ is zero or very close to zero.

In our case, after sensor fault, the control-strategy-decision block generates a logical variable to select the appropriate control method. The transition strategy is to authorize controller switchover when the control voltages are naturally synchronized $(\Delta \theta=0)$. This will lead to a real smooth transition with no abrupt change in the torque. Unfortunately, it is very difficult to get this condition, as illustrated by Fig. 5. This fact has led us to consider fuzzy logic to set a switchover block with contribution from two neighbor controllers (Section III).

For comparison purposes, in [47], the transition technique is to force synchronization between the encoder-based angle generator and the SVC angle generator by compensating for their phase difference at the instant of controller switchover.

\section{B. Tests of the Fault-Tolerant Controller}

The proposed fault-tolerant control strategy has been simulated on a $4-\mathrm{kW}$ induction-motor drive, whose ratings are summarized in the Appendix. The proposed system adaptively reorganizes itself in the event of mechanical speed and/or current sensor loss or recovery to sustain the best control performance.

In Figs. 6 and 7, a set of speed and torque curves show the controller smooth transitions $(\Delta \theta=0)$ and abrupt ones $(\Delta \theta \neq 0)$. The following event sequences were implemented: 1) At $0.5 \mathrm{~s}$, a disturbance was introduced, in which the 


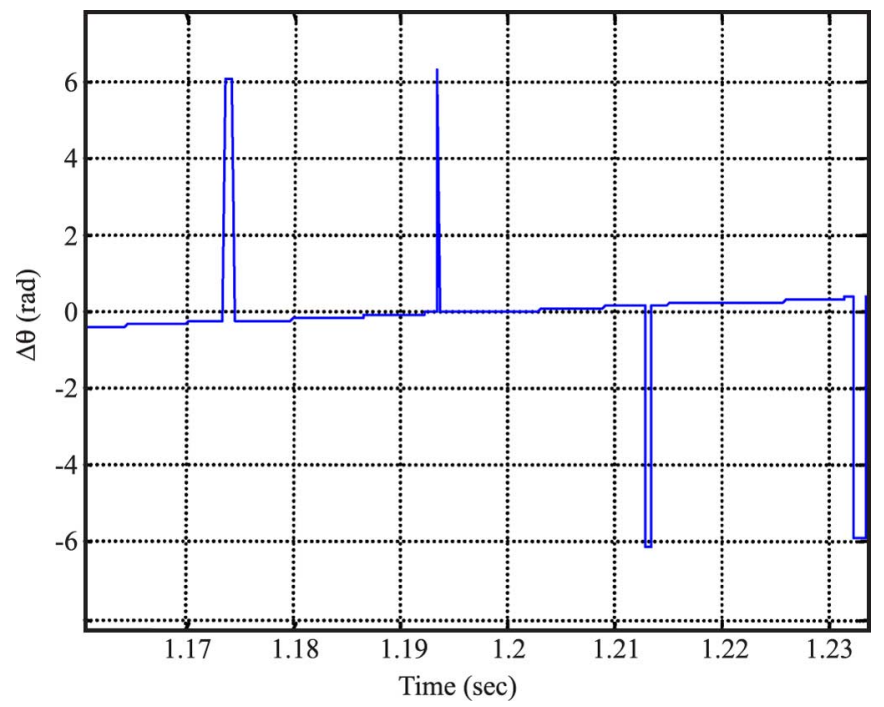

Fig. 5. Rotor-flux-angular phase-shift for a vector and a scalar control of the induction-motor drive.

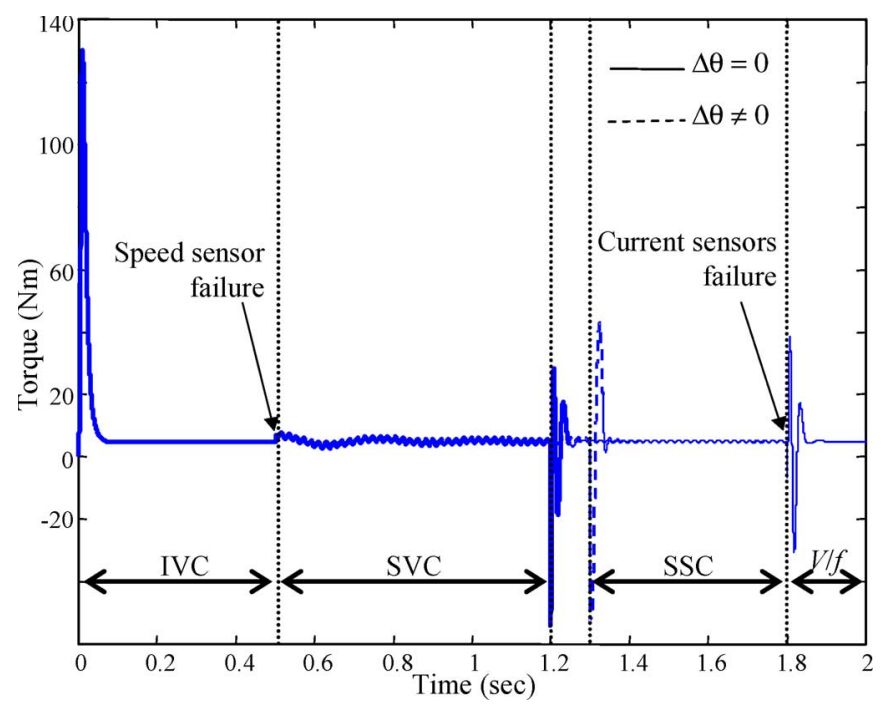

Fig. 6. Torque response according to controller transitions.

speed-sensor pulses were missed (speed-sensor failure). 2) At $1.2 \mathrm{~s}$, the rotor-flux orientation cannot be maintained (e.g., access to the rotor-flux angle was lost). Thus, there is the need for a scalar-control method to guarantee the stability.

As expected and shown in Fig. 6, dynamic performances have deteriorated. 3) At $1.8 \mathrm{~s}$, current sensors have failed. The Volts/Hertz control technique is then engaged. It is the last step in the hierarchical classification of the control strategies for the induction-motor drive. Although voltage sensors are typically not used, the application of a desired voltage to the induction motor without the need for voltage sensors implies that the inverter-bus voltage is known.

Generally, we observe an oscillatory behavior when the speed sensor fails. The torque oscillations, for $\Delta \theta=0$, have a small amplitude with an almost null average and are quickly damped. On the contrary, when $\Delta \theta \neq 0$, the average torque is negative leading to a braking torque, which is confirmed by the speed deceleration illustrated by Fig. 7 .

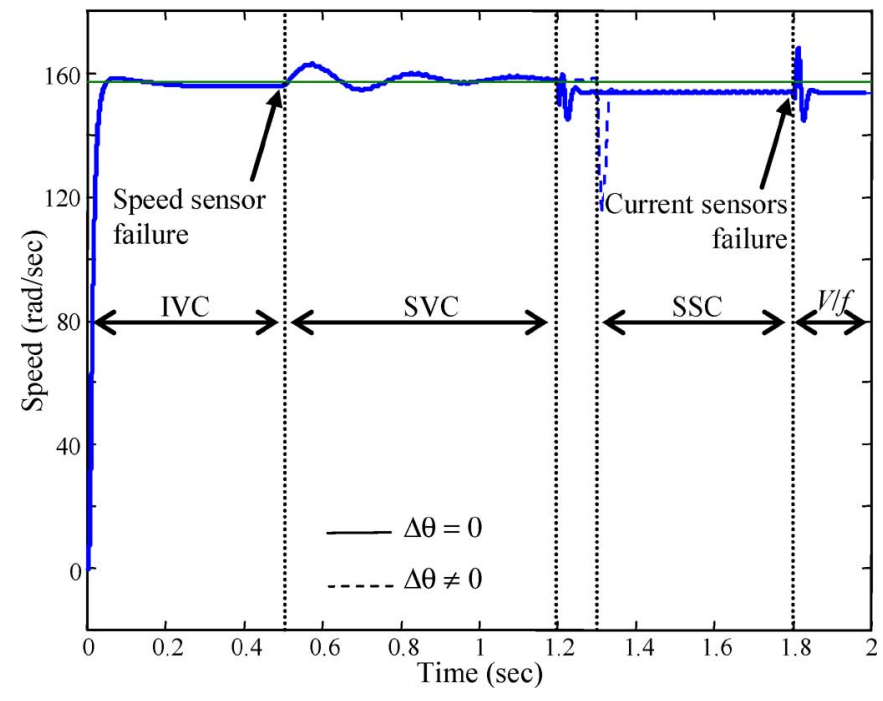

Fig. 7. Speed response according to controller transitions.

\section{Fault-Tolerant Control With Modern and INTELLIGENT TECHNIQUES}

In this second approach, the fault-tolerant control system first concerns the SMC technique since better performance is obtained with an encoder to get the speed information [53]. In the event of unavailability of the speed sensor, a sensorless FC (FVBC) technique is applied [54].

Fig. 8 shows the proposed flexible architecture for faulttolerant control purposes. The fuzzy switchover block (FSB) consists of a fuzzification operation, a rule base, a database, and a defuzzification operation.

\section{A. Why the SMC?}

In general, the field-oriented control performance is sensitive to the deviation of motor parameters, particularly the rotor time constant. To deal with this problem, there are many flux measurement and estimation mechanisms in the published literature [55]. However, flux measurement with Hall sensors will usually produce the problem of degradation in mechanical robustness and increase cost or volume. Therefore, flux estimation is a more suitable method for field-oriented control than direct flux measurement. However, the common problem is the estimation accuracy and robustness under the possible occurrence of uncertainties.

SMC is one of the effective nonlinear robust control approaches, since it provides system dynamics with an invariant property to uncertainties once the system dynamics are controlled in the sliding mode [56].

\section{B. Why FC?}

The application of fuzzy-based-control strategies has recently gained enormous recognition as an approach for the rapid development of effective controllers for nonlinear timevariant systems. Over the years, fuzzy-logic techniques have been applied to a wide range of systems, with many electronic control systems in the automotive industry, such as automatic 


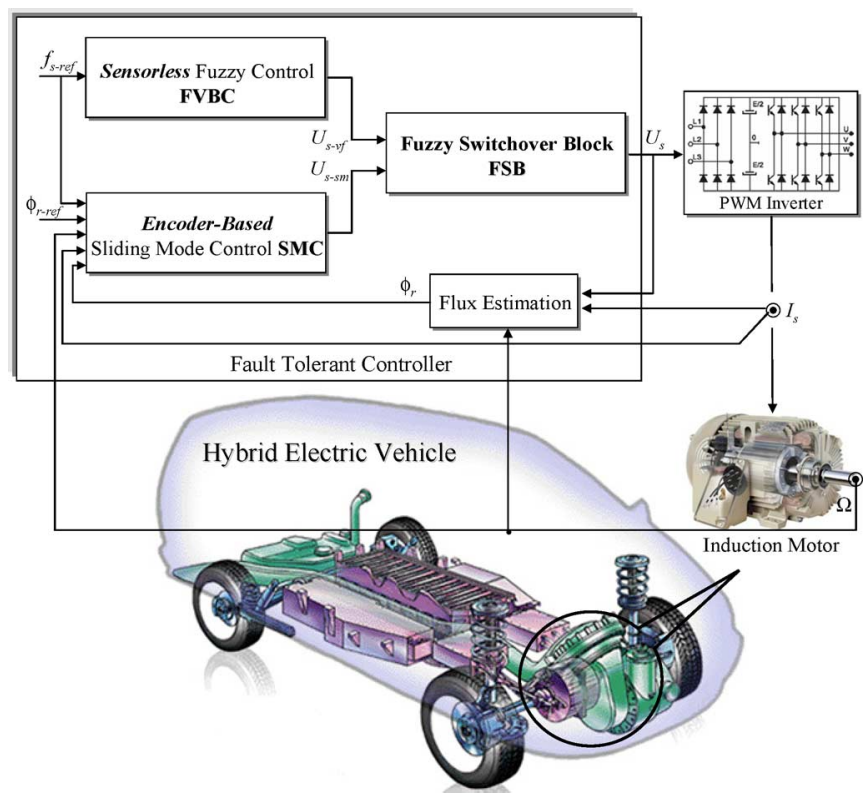

Fig. 8. Fault-tolerant controller configuration.

transmission, engine control, and antilock-braking systems. These electronically controlled automotive systems realize superior characteristics through the use of fuzzy-logic-based control, rather than traditional control algorithms [57]. Moreover, since fuzzy-logic controllers deal with inexactness in a rigorous manner, they are effective at handling the uncertainties and nonlinearities associated with complex control systems such as traction control [58]-[60].

The FVBC controller has been chosen, because it meets the EVs or HEVs requirement for optimizing (maximizing) the induction motor efficiency. In fact, the losses are minimized when the motor operates at low frequency and with rated torque. Moreover, the starting torque is also greatly improved, increasing the drive capabilities in the low-speed region [54]. Moreover, the switchover block is, in this second case, based on fuzzy logic. Indeed, the controller transition that is a sensitive but complex task is better handled with a fuzzy approach.

\section{Controller-Transition Strategy}

The main idea of the FSB is to generate the suitable law $U_{s}$ in order to compensate for the existing drift between $U_{\mathrm{s}-\mathrm{sm}}$ and

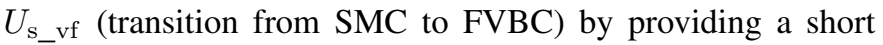
transition between both controllers. The suitable laws $U_{s}$ can be written as

$$
\bar{U}_{s}=f\left(\bar{U}_{\mathrm{s}-\mathrm{vf}}, \bar{U}_{\mathrm{s}-\mathrm{sm}}\right)=(1-\mathrm{SF}) \bar{U}_{\mathrm{s}-\mathrm{vf}}+\mathrm{SF} \bar{U}_{\mathrm{s}-\mathrm{sm}}
$$

where $U_{\mathrm{s} \_v f}$ is the stator voltage generated by the FVBC, $U_{\mathrm{s}-\mathrm{sm}}$ is the stator voltage generated by SMC, and SF is the switching function.

1) Fuzzy Database: The fuzzy-switchover law has the internal structure of an expert system. It samples error signals $\Delta \Omega$ and $\Delta I_{s}$ at each sampling instant. Its output is the variable SF. The FSB inputs are defined by

$$
\left\{\begin{array}{l}
e_{1}(k)=\Delta \Omega(k)=\Omega_{\mathrm{ref}}(k)-\Omega(k) \\
e_{2}(k)=\Delta I_{s}(k)=I_{s}(k)-I_{s}(k-1)
\end{array}\right.
$$

where $I_{s}$ is the stator current and $\Omega$ the rotor speed.

Fig. 9(a) and (b) illustrates the fuzzy subsets and the corresponding membership functions describing the normalized input variables. Fig. 9(c) describes the output variable SF that modulates the controller voltage between sliding mode and scalar-control strategies.

2) Fuzzy-Rule Base: Knowledge is extracted in terms of if-then fuzzy rules. The list of the extracted rules is given in Table I. The rules are observed to be in agreement with the system knowledge. They are consistent with our expectations. Moreover, some of the presented cases are not concerned by fault-tolerant operation. In this situation, the SMC technique is selected since it has been proven to offer the best transient and steady-state performance over the entire speed range. To be absolutely sure that input variable changes are only due to encoder anomalies, the FSB is only activated in steady state by detecting the variation rate of the torque current $I_{\mathrm{sq}}$ since the problem of parameter variations is solved.

\section{Tests of the Fault-Tolerant Controller}

The proposed fault-tolerant control strategy has been simulated on the same 4-kW induction-motor drive.

In Fig. 10, the mechanical speed-sensor loss in terms of missing encoder output pulses is plotted. At $1.5 \mathrm{~s}$, no more information is given to the controller from the speed sensor, and a second later, the sensor is recovered.

At $t=1.5 \mathrm{~s}$, the rotor speed begins to decrease (Fig. 11). Therefore, the FSB reconfigures the control from SMC to the sensorless FVBC. The FVBC then restores the correct system performance after a short torque transition, as illustrated by Fig. 12. At $t=2.5 \mathrm{~s}$, the encoder failure is removed. Therefore, the FSB switches back to the SMC (encoder-based control). A small torque transition is observed and is clearly related to the stator-current variation (Fig. 13).

The main function of the FSB [Fig. 14(a)] is to force synchronization between the encoder-based controller (SMC) and the sensorless controller (FVBC). It should be noted in this case that one of the main advantages of fuzzy logic is the switchover-block ability to get contribution from the two neighbor controllers, as expected, using (2), and it is shown by Fig. 14(b), which is a zoom of Fig. 14(a). The output is not equal to zero or one, thus revealing a contribution of both controllers.

\section{COMPARISON AND CONCLUDING REMARKS}

This paper has described active fault-tolerant-control systems for a high-performance induction-motor drive for automotive applications (propulsion of EVs or HEVs).

The proposed systems adaptively reorganize themselves in the event of mechanical speed and/or current sensor loss or 


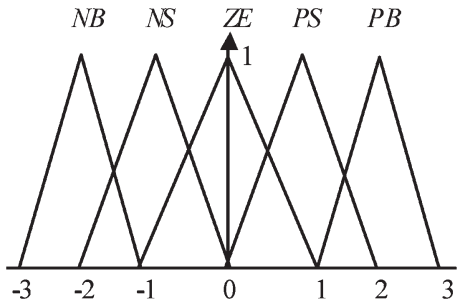

(a)

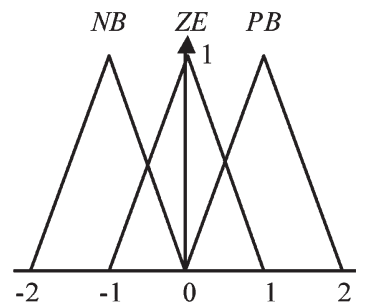

(b)

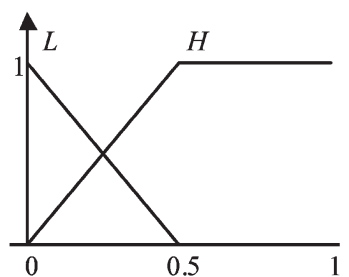

(c)

Fig. 9. FSB membership functions. (a) Input variable $e_{1}$. (b) Input variable $e_{2}$. (c) Output variable SF.

TABLE I

LINGUISTIC RULES FOR THE FSB

\begin{tabular}{|l|c|c|c|c|c|c|}
\cline { 2 - 6 } \multicolumn{1}{l|}{} & $e_{1}$ & $N B$ & $N S$ & $Z E$ & $P S$ & $P B$ \\
\cline { 1 - 5 }$e_{2}$ & $S F$ & & & & & \\
\hline$N B$ & & $H$ & $H$ & $H$ & $H$ & $H$ \\
\hline$Z E$ & $L$ & $L$ & $H$ & $L$ & $L$ \\
\hline$P B$ & $H$ & $H$ & $H$ & $H$ & $H$ \\
\hline
\end{tabular}

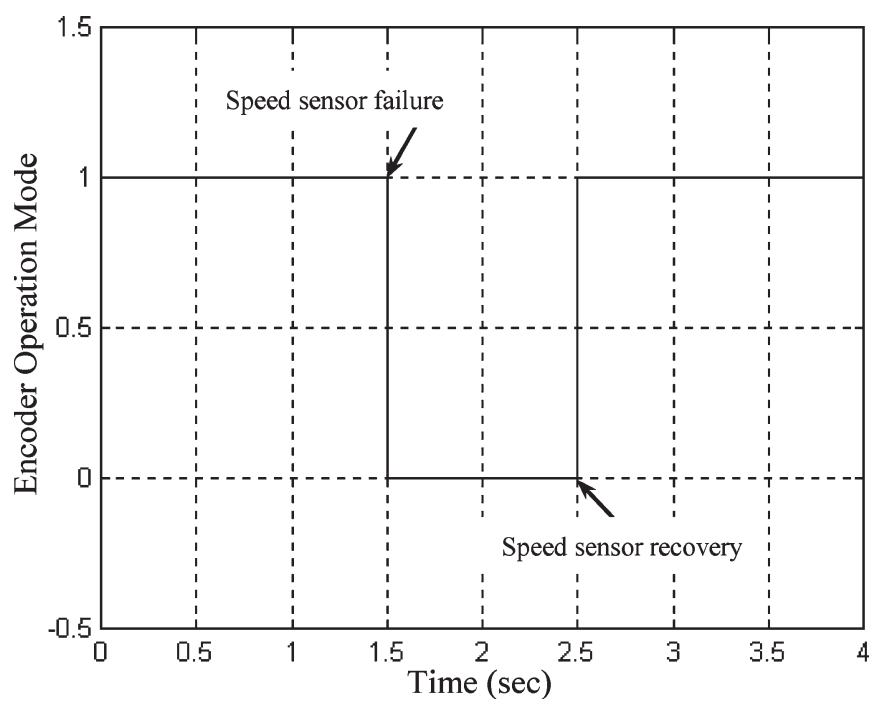

Fig. 10. Transitions from SMC to FVBC and back to SMC: Encoder operation mode.

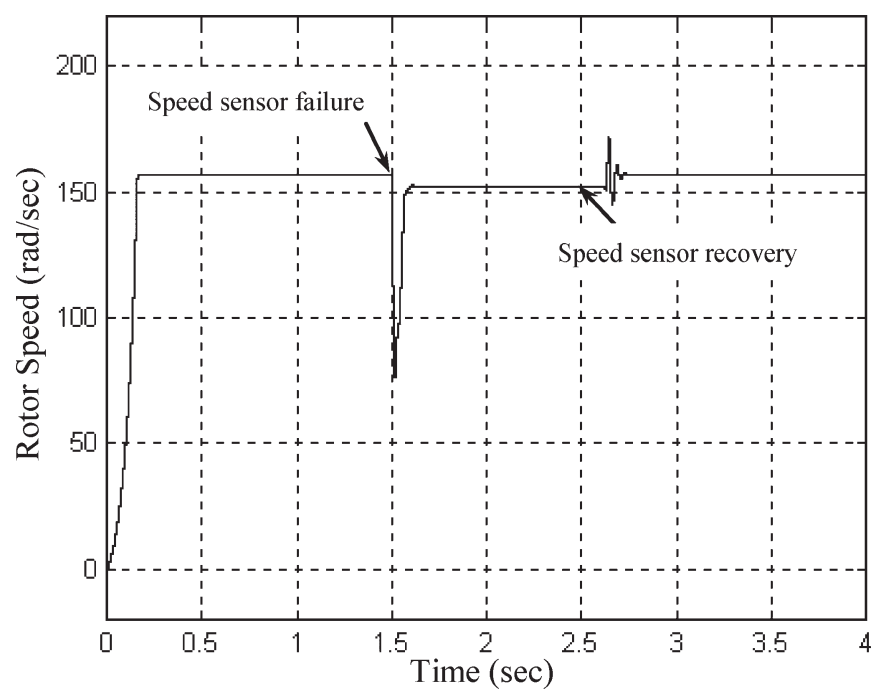

Fig. 11. Transitions from SMC to FVBC and back to SMC: Rotor speed.

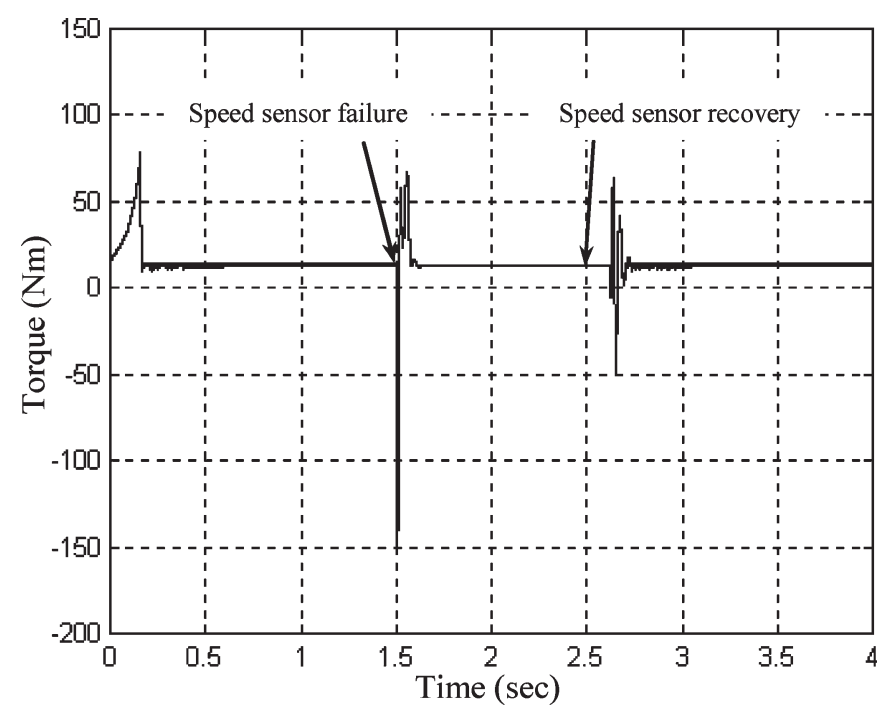

Fig. 12. Transitions from SMC to FVBC and back to SMC: Torque.

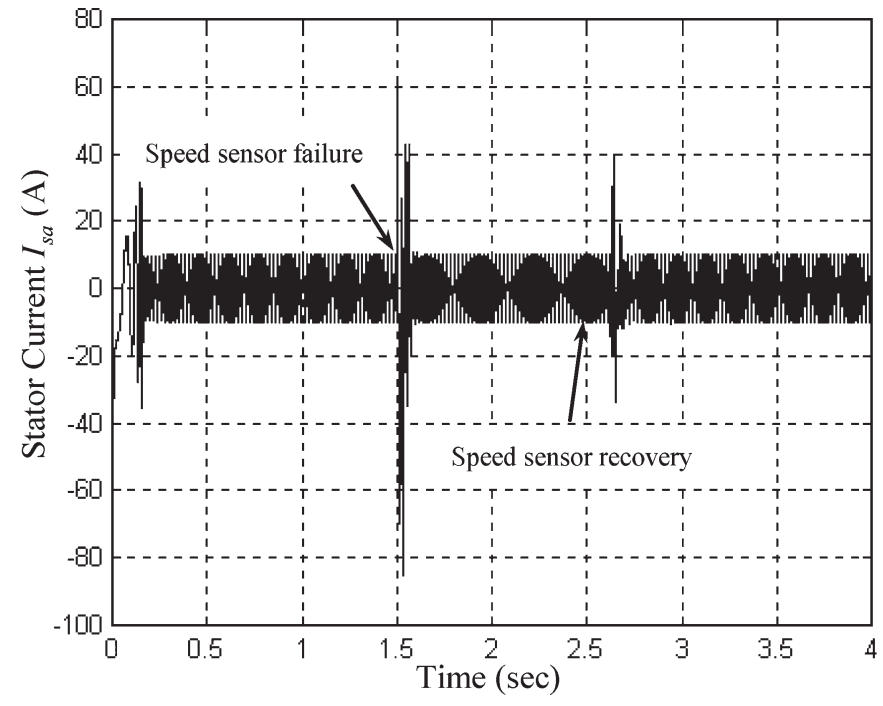

Fig. 13. Transitions from SMC to FVBC and back to SMC: Stator current.

sensor recovery to sustain the best control performance, given the complement of remaining sensors. The FDI block computes the actual state from the available measurements, and the supervision one makes the decision on the strategy. Moreover, the developed systems take into account the controller-transition smoothness in terms of speed and torque transients. Indeed, a 


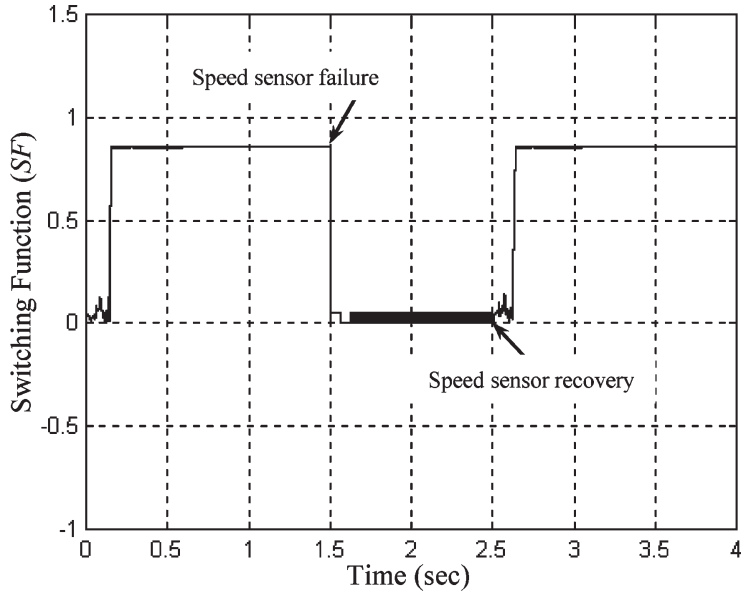

(a)

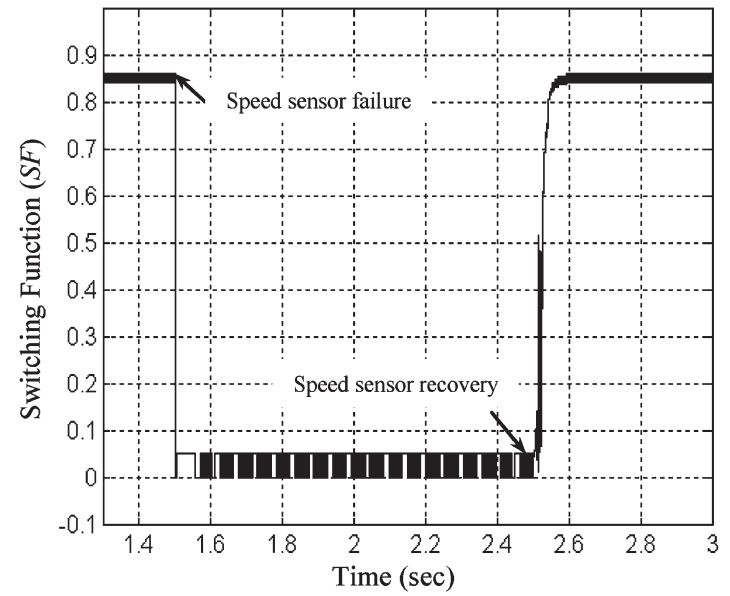

(b)

Fig. 14. Transitions from SMC to FVBC and back to SMC. (a) Switching function. (b) Zoom.

management technique has been introduced to assure smooth transition between two control techniques in case of sensor failures.

The two proposed fault-tolerant control strategies have been simulated on a 4-kW induction-motor drive. Simulation results, in terms of speed and torque responses, show the global effectiveness of both approaches, particularly the one based on modern and intelligent-control techniques.

For the so-called "classical" approach in which a single control strategy is involved, the transition technique is to authorize controller switchover when the modulation sinusoidal voltages used to generate the PWM signals are naturally synchronized $(\Delta \theta=0)$. This will lead to a real smooth transition with no abrupt change in the torque. Unfortunately, it is very difficult to get this condition fulfilled, as illustrated by Fig. 5. This fact has led us to introduce artificial-intelligence techniques (fuzzy logic in this case) to set a switchover block with a contribution from the two neighbor controllers. Moreover, in the case of no fault-tolerant operation, this fuzzy block has the advantage of selecting the best controller (control technique) that offers the best transient and steady-state performance over the entire speed range.
APPENDIX

RATED DATA of THE Simulated Induction Motor

\begin{tabular}{llll}
\hline Rated Values & Power & 4 & $\mathrm{KW}$ \\
& Frequency & 50 & $\mathrm{~Hz}$ \\
& Voltage $(\Delta / \mathrm{Y})$ & $220 / 380$ & $\mathrm{~V}$ \\
& Current $(\Delta / \mathrm{Y})$ & $15 / 8.6$ & $\mathrm{~A}$ \\
& Speed & 1440 & $\mathrm{rpm}$ \\
& Pole pair $(\mathrm{p})$ & 2 & \\
Rated parameters & $R_{S}$ & 1.2000 & $\Omega$ \\
& $R_{r}$ & 1.8000 & $\Omega$ \\
& $L_{S}$ & 0.1554 & $\mathrm{H}$ \\
& $L_{r}$ & 0.1566 & $\mathrm{H}$ \\
Rated parameters & $M$ & 0.1500 & $\mathrm{H}$ \\
& $J$ & 0.024 & $\mathrm{~kg} . \mathrm{m}^{2}$ \\
& $f$ & 0.011 & $\mathrm{IS}$ \\
\hline
\end{tabular}

\section{REFERENCES}

[1] D. Diallo et al., "A fault-tolerant control architecture for induction motor drives in automotive applications," IEEE Trans. Veh. Technol., vol. 53, no. 6, pp. 1847-1855, Nov. 2004.

[2] M. E. H. Benbouzid et al., "Active fault-tolerant control of induction motor drives in EV and HEV against sensor failures using a fuzzy decision system," in Proc. IEEE IEMDC, 2003, vol. 2, pp. 677-683.

[3] C. C. Chan, "The state of the art of electric and hybrid vehicles," Proc. IEEE, vol. 90, no. 2, pp. 247-275, Feb. 2002.

[4] M. E. H. Benbouzid et al., "A loss-minimization DTC scheme for EV induction motors," in Proc. IEEE VPPC, Chicago, IL, Sep. 2005, pp. 315-321.

[5] T. M. Jahns et al., "Recent advances in power electronics technology for industrial and traction machine drives," Proc. IEEE, vol. 89, no. 6, pp. 963-975, Jun. 2002.

[6] M. Zeraoulia et al., "Electric motor drive selection issues for HEV propulsion systems: A comparative study," in Proc. IEEE VPPC, Chicago, IL, Sep. 2005, pp. 280-286.

[7] W. Leonhard, Control of Electrical Drives. Berlin, Germany: SpringerVerlag, 1985.

[8] C. M. Ta et al., "Convergence improvement of efficiency-optimization control of induction motor drives," IEEE Trans. Ind. Appl., vol. 37, no. 6, pp. 1746-1754, Nov./Dec. 2001.

[9] D. O. Neacsu et al., "Comparative analysis of torque-controlled IM drives with applications in electric and hybrid vehicles," IEEE Trans. Power Electron., vol. 16, no. 2, pp. 240-247, Mar. 2001.

[10] J. Jung et al., "A vector control schemes for EV induction motors with a series iron loss model," IEEE Trans. Ind. Electron., vol. 45, no. 4, pp. 617-624, Aug. 1998.

[11] N. Mutoh et al., "A torque controller suitable for electric vehicles," IEEE Trans. Ind. Electron., vol. 44, no. 1, pp. 54-63, Feb. 1997.

[12] C. Lascu et al., "A sensorless hybrid DTC drive for high-volume low-cost applications," IEEE Trans. Ind. Electron., vol. 51, no. 5, pp. 1048-1055, Oct. 2004.

[13] J. Faiz et al., "Sensorless direct torque control of induction motors used in electric vehicle," IEEE Trans. Energy Convers., vol. 18, no. 1, pp. 1-10, Mar. 2003.

[14] $~$, "Different techniques for real time estimation of an induction motor rotor resistance in sensorless direct torque control for electric vehicle," IEEE Trans. Energy Convers., vol. 16, no. 1, pp. 104-109, Mar. 2001.

[15] C. C. Chan et al., "Adaptive decoupling control of induction motor drives," IEEE Trans. Ind. Electron., vol. 37, no. 1, pp. 41-47, Feb. 1990.

[16] V. I. Utkin, "Sliding mode control design principles and applications to electric drives," IEEE Trans. Ind. Electron., vol. 40, no. 1, pp. 23-36, Feb. 1993.

[17] A. B. Proca et al., "Sensorless sliding-mode control of induction motors using operating condition dependent models," IEEE Trans. Energy Convers., vol. 18 , no. 2, pp. 205-212, Jun. 2003. 
[18] M. Jalili-Kharaajoo et al., "Sliding mode traction control of an electric vehicle with four separate wheel drives," in Proc. IEEE ETFA, 2003, vol. 2, pp. 291-296.

[19] Z. Chen et al., "Neural networks based electric motor drive for transportation systems," in Proc. IEEE ITS, 2003, vol. 2, pp. 1378-1383.

[20] _ - "Neural network control of electric machines for transportation systems," in Proc. IEEE ICSMC, 2003, vol. 2, pp. 1904-1909.

[21] B. Asaii et al., "A new technique for highly efficient sensor-less control of electric vehicles by using neural networks," in Proc. IEEE PETC, 1996, pp. 143-149.

[22] R. B. Sepe et al., "HEV S/G (hybrid electric vehicle starter/generator)," IEEE Ind. Appl. Mag., vol. 9, no. 3, pp. 38-43, May/Jun. 2003.

[23] H. D. Lee et al., "Torque control strategy for a parallel-hybrid vehicle using fuzzy logic," IEEE Ind. Appl. Mag., vol. 6, no. 6, pp. 33-38, Nov./Dec. 2000

[24] B. M. Baumann et al., "Mechatronic design and control of hybrid electric vehicles," IEEE/ASME Trans. Mechatronics, vol. 5, no. 1, pp. 58-72, Mar. 2000.

[25] H. Huang et al., "Electrical two-speed propulsion by motor winding switching and its control strategies for electric vehicles," IEEE Trans. Veh. Technol., vol. 48, no. 2, pp. 607-618, Mar. 1999.

[26] H. D. Lee et al., "Fuzzy-logic-based torque control strategy for paralleltype hybrid electric vehicle," IEEE Trans. Ind. Electron., vol. 45, no. 4, pp. 625-632, Aug. 1998.

[27] B. K. Bose et al., "A neuro-fuzzy-based on-line efficiency optimization control of a stator flux-oriented direct vector-controlled induction motor drive," IEEE Trans. Ind. Electron., vol. 44, no. 2, pp. 270-273, Apr. 1997.

[28] P. H. Chen, "Application of fuzzy intelligence to Elebike control design," in Proc. IEEE ICFS, 1997, vol. 1, pp. 199-206.

[29] G. El-Saady et al., "An error driven hybrid neuro-fuzzy torque/speed controller for electrical vehicle induction motor drive," in Proc. IEEE IVS, 1994, pp. 449-454.

[30] Z. Rahman et al., "An investigation of electric motor drive characteristics for EV and HEV propulsion systems," presented at the SAE Tech. Paper Series, Costa Mesa, CA, 2000, Paper 2000-01-3062.

[31] C. Chakraborty et al., "Speed sensorless efficiency optimized control of induction motor drives suitable for EV," in Proc. IEEE IECON, 2003, vol. 1, pp. 913-918.

[32] E. Nordlund et al., "The four quadrant energy transducer," in Proc. IEEE IAS, 2002, pp. 236-241.

[33] K. Jezernik, "Speed sensorless torque control of induction motor for EV's," in Proc. IEEE IWAMC, 2002, vol. 1, pp. 913-918.

[34] M. Chis et al., "Neural network-based efficiency optimization of EV drive," in Proc. IEEE CCECE, 1997, vol. 2, pp. 454-461.

[35] — "Efficiency optimization of EV drive using fuzzy logic," in Proc. IEEE IAS, 1997, vol. 2, pp. 934-941.

[36] B. A. Welchko et al., "Fault tolerant three-phase ac motor drive topologies: A comparison of features, cost, and limitations," IEEE Trans. Power Electron., vol. 19, no. 4, pp. 1108-1116, Jul. 2004.

[37] N. E. Wu, "Coverage in fault-tolerant control," Automatica, vol. 40, no. 4, pp. 537-548, 2004.

[38] C. Bonivento et al., "Implicit fault-tolerant control: Application to induction motors," Automatica, vol. 40, no. 3, pp. 355-371, 2004.

[39] J. Klima, "Analytical investigation of an induction motor drive under inverter fault mode operations," Proc. Inst. Electr. Eng.-Electric Power Appl., vol. 150, no. 3, pp. 255-262, May 2003.

[40] M. B. de Rossier Corrêa et al., "An induction motor drive system with improved fault tolerance," IEEE Trans. Ind. Appl., vol. 37, no. 5, pp. 873879, May/Jun. 2001

[41] C. J. Lopez-Toribio et al., "Takagi-Sugeno fuzzy fault-tolerant control of an induction motor," Neural Comput. Appl., vol. 9, no. 1, pp. 19-28, 2000.

[42] D. Kastha et al., "Investigation of fault modes of voltage-fed inverter system for induction motor drive," IEEE Trans. Ind. Appl., vol. 30, no. 4, pp. 426-433, Jul./Aug. 1994.

[43] T. H. Liu et al., "A strategy for improving reliability of field-oriented controlled induction motor drives," IEEE Trans. Ind. Appl., vol. 29, no. 5, pp. 910-918, Sep./Oct. 1993.

[44] C. Thybo, "Fault-tolerant control of induction motor drive applications," in Proc. IEEE ACC, 2001, vol. 4, pp. 2621-2622.

[45] K. S. Lee et al., "Instrument fault detection and compensation scheme for direct torque controlled induction motor drives," Proc. Inst. Electr. Eng.-Control Theory Appl., vol. 150, no. 4, pp. 376-382, Jul. 2003.

[46] S. Mir et al., "Fault-tolerant switched reluctance motor drive using adaptive fuzzy logic controller," IEEE Trans. Power Electron., vol. 19, no. 2, pp. 289-295, Mar. 2004.
[47] R. B. Sepe et al., "Fault tolerant operation of induction motor drives with automatic controller reconfiguration," in Proc. IEEE IEMDC, 2001 , pp. 156-162.

[48] Y. S. Jeong et al., "Fault detection and fault-tolerant control of interior permanent-magnet motor drive system for electric vehicle," IEEE Trans. Ind. Appl., vol. 41, no. 1, pp. 46-51, Jan./Feb. 2005.

[49] L. Parsa et al., "A self reconfigurable electric motor controller for hybrid electric vehicle applications," in Proc. IEEE IECON, 2003, vol. 1, pp. 919-924.

[50] H. Chen et al., "A novel green electric drive system," in Proc. IEEE ICSMC, 2001, vol. 5, pp. 3157-3162.

[51] S. M. Bennett et al., "Sensor fault-tolerant control of a rail traction drive," Control Eng. Pract., vol. 7, no. 2, pp. 217-225, Feb. 1999.

[52] M. E. H. Benbouzid et al., "A practical scheme for induction motor speed sensorless field oriented control," IEEE Trans. Energy Convers., vol. 19, no. 1, pp. 230-231, Mar. 2004.

[53] A. Benchaïb et al., "Real-time sliding mode observer and control of induction motor," IEEE Trans. Ind. Electron., vol. 46, no. 1, pp. 128-138, Feb. 1999.

[54] D. Diallo et al., "Fuzzy optimal Volts/Hertz control method for an induction motor," in Proc. IEEE IEMDC, 2001, vol. 1, pp. 377-381.

[55] H. A. Toliyat et al., "A review of RFO induction motor parameter estimation techniques," IEEE Trans. Energy Convers., vol. 18, no. 2, pp. 271283, Jun. 2003.

[56] K. D. Young et al., "A control engineer's guide to sliding mode control," IEEE Trans. Control Syst. Technol., vol. 7, no. 3, pp. 328-342, May 1999.

[57] P. M. De Koker et al., "Fuzzy control algorithm for automotive traction control systems," in Proc. IEEE MELECON, 1996, vol. 1, pp. 226-229.

[58] R. Pusca et al., "Fuzzy-logic-based control applied to a hybrid electric vehicle with four separate wheel drives," Proc. Inst. Electr. Eng.-Control Theory Appl., vol. 151, no. 1, pp. 73-81, Jan. 2004.

[59] P. Khatun et al., "Application of fuzzy control algorithms for electric vehicle antilock braking/traction control systems," IEEE Trans. Veh. Technol., vol. 52, no. 5, pp. 1356-1364, Sep. 2003.

[60] N. J. Schouten et al., "Fuzzy logic control for parallel hybrid vehicles," IEEE Trans. Control Syst. Technol., vol. 10, no. 3, pp. 460-468, May 2002.

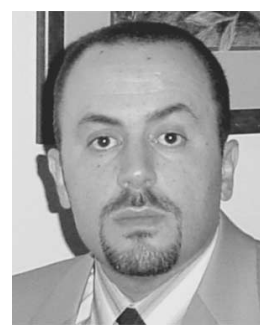

Mohamed El Hachemi Benbouzid (S'92-M'95SM'98) was born in Batna, Algeria, in 1968. He received the B.Sc. degree in electrical engineering from the University of Batna, in 1990, and the M.Sc. and Ph.D. degrees in electrical and computer engineering from the National Polytechnic Institute of Grenoble, Grenoble, France, in 1991 and 1994, respectively. He received the Habilitation à Diriger des Recherches degree from the University of Picardie "Jules Verne," Amiens, France, in November 2000.

After graduation, he joined the University of Picardie "Jules Verne," where he was an Associate Professor of electrical and computer engineering with the Professional Institute of Amiens. In September 2004, he joined the IUT of Brest, University of Western Brittany, Brest, France, as a Professor of electrical engineering. His main research interests and experience include analysis, design, and control of electric machines, variablespeed drives for traction and propulsion applications, and fault diagnosis of electric machines.

Prof. Benbouzid is a Senior Member of the IEEE Power Engineering, Industrial Electronics, Industry Applications, Power Electronics, and Vehicular Technology Societies. He is an Associate Editor of the IEEE TRANSACTIONS ON ENERGY CONVERSION, the IEEE TRANSACTIONS ON INDUSTRIAL ELECTRONICS, the IEEE TRANSCATIONS ON VeHICUlar TECHNOLOGY, and the IEEE/ASME TRANSACTIONS ON MECHATRONICS. 


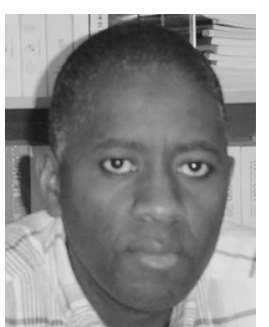

Demba Diallo (M'99-SM'05) was born in Dakar, Senegal, in 1966. He received the M.Sc. and Ph.D. degrees in electrical and computer engineering from the National Polytechnic Institute of Grenoble, Grenoble, France, in 1990 and 1993, respectively, and the Habilitation à Diriger des Recherches degree from the University of Paris XI, Gif-Sur-Yvette, France, in December 2005.

From 1994 to 1999 , he worked as a Research Engineer in the Laboratoire d'Electrotechnique de Grenoble on electrical drives and active filters (hardware and software). In 1999, he joined the University of Picardie "Jules Verne," Amiens, France, as Associate Professor of electrical engineering. In September 2004, he joined the IUT of Cachan, University of Paris XI, as an Associate Professor of electrical engineering. He is currently with the Laboratoire de Génie Electrique de Paris. His current area of research includes advanced control techniques and diagnosis in the field of ac drives.

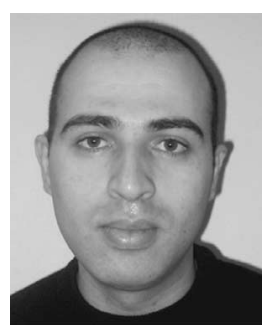

Mounir Zeraoulia (S'04) was born in Yabous, Algeria, in 1975. He received the B.Sc. degree in electronics from the University of Batna, Batna, Algeria, in 2000, and the M.Sc. degree in electronics from the University of Valenciennes, Valenciennes, France, in 2002. He is currently working toward the Ph.D. degree in hybrid-electrical-vehicle control.

$\mathrm{He}$ is currently with the Laboratoire d'Ingénierie Mécanique et Electrique (LIME), IUT of Brest, University of Western Brittany, Brest, France. 